\title{
Ischemic colitis following infrarenal abdominal aortic aneurysm treatment: Results from a tertiary medical center
}

\author{
Ulas Aday, ${ }^{1}$ Ebubekir Gundes, ${ }^{1}$ Durmus Ali Cetin, ${ }^{1}$ Huseyin Ciyiltepe, ${ }^{1}$ Aziz Serkan Senger, ${ }^{1}$ \\ Selcuk Gulmez, ${ }^{1}$ Mustafa Akbulut, ${ }^{2}$ Erdal Polat ${ }^{1}$ \\ ${ }^{1}$ Department of Gastroenterological Surgery, Kartal Kosuyolu High Speciality and Training Hospital, Istanbul, Turkey \\ 2Department of Cardiovascular Surgery, Kartal Kosuyolu High Speciality and Training Hospital, Istanbul, Turkey
}

\begin{abstract}
OBJECTIVE: The aim of this study was to investigate the effects of ruptured aneurysm on morbidity and mortality in patients with ischemic colitis (IC) and resection following infrarenal abdominal aortic aneurysms (AAA) surgery.

METHODS: Between January 2012 and December 2016, patients who underwent resection for ischemic colitis in our clinic were retrospectively reviewed. Data on the ruptured condition of the aneurysm, the emergency or elective form of aneurysm surgery, treatment method for the aneurysm (EVAR-open) were obtained. The patients were compared and divided into two groups as those with ruptured aneurysm and those without.

RESULTS: A total of 275 infrarenal AAA cases were treated by the cardiovascular surgery clinic between January 2012 and December 2016. Fourteen patients (5\%) developed ischemic colitis requiring resection. Four (1.8\%) patients with EVAR and $10(17.5 \%)$ patients with open surgery were operated because of IC. No statistically significant difference was observed between the two groups in terms of demographic data and surgical procedures. The intergroup comparison did not reveal any statistically significant difference among gastrointestinal (GIS) symptoms, the time period until surgery, the involved colon segment, and the surgical procedures performed. The mortality rate in ruptured AAA group was $83.3 \%$, while it was $62.5 \%$ in the non-ruptured AAA group. In spite of the fact that the mortality rate was high in the ruptured group, it was not statistically significant $(p=0.393)$.

CONCLUSION: IC is a complication of AAA surgery with a high mortality rate. Rupture in abdominal aortic aneurysm increasing mortality in IC patients. This complication with a high mortality rate following open AAA surgery should be noted by surgeons and we believe that the liberal utilization of laparotomy and early intervention in suspected cases will decrease mortality rates.
\end{abstract}

Keywords: Abdominal aortic aneurysms; ischemic colitis; ruptured aneurysm; surgery.

Cite this article as: Aday U, Gundes E, Cetin DA, Ciyiltepe H, Senger AS, Gulmez S, et al. Ischemic colitis following infrarenal abdominal aortic aneurysm treatment: Results from a tertiary medical center. North Clin Istanb 2018;5(3):221-226.

Tschemic colitis (IC) is a complication with a very high 1 mortality rate that may develop following the repair of abdominal aortic aneurysms (AAA) by open and endovascular (EVAR) methods $[1,2]$. The rates of resection performed because of IC in ruptured AAA surgery can go as high as $14 \%$. Currently, endovascular aortic repair (EVAR) is commonly used as a minimally invasive method for aneurysm treatment. The IC rates following EVAR have considerably decreased $[3,4]$. Severe IC results in full-thickness necrosis perforation of the bowel

Received: June 05, 2017 Accepted: October 30, 2017 Online: May 25, 2018

Correspondence: Dr. Ulas ADAY. Kartal Kosuyolu Yuksek Ihtisas Egitim ve Arastirma Hastanesi, Gastroenteroloji Cerrahi Klinigi, Istanbul, Turkey

Phone: +9021650050 01 e-mail: ulasaday@gmail.com

(c) Copyright 2018 by Istanbul Provincial Directorate of Health - Available online at www.northclinist.com 
wall, and its rapid clinical progress gives way to multiple organ failure and mortality [5]. Resection and frequent stoma formation by early identification are crucial in the management of this picture with a high mortality rate [6].

Studies have identified many risk factors for IC. It has been observed that conditions such as old age, female sex, renal failure, ruptured aneurysm, emergency surgery, inotropic support, massive blood loss, prolonged surgery, duration of aortic clamping, open surgery, diabetes mellitus (DM), coronary artery disease (CAD), hypertension, chronic obstructive pulmonary disease (COPD), smoking, shaggy aorta, and occluded inferior mesenteric artery (IMA) increased the risk of IC and mortality [13, 6-9]. Most of the studies have presented more than one risk factor. The presence of more than one comorbid condition, previous history of major abdominal vascular surgery, time between the diagnosis and teratment of IC, and additional surgical load like laparotomy and resection in such patients render very high mortality rates $[1$, 9]. IC frequently manifests with segmental and left colon involvement. It has been reported that the rate of IC was as high as $42 \%$ as seen in colonoscopic controls following emergency procedures because of ruptured AAA. Cases with ruptured AAA frequently receive emergency surgical procedures; it has also been stated that IC and mortality rates were higher and thus had negative effects on prognosis $[1,3,6,10,11]$. A majority of these cases were IC cases limited to the mucosa and muscular layer (Grade I-II), and the rate of severe IC (Grade III) has been reported to be between $8.9 \%$ and $14 \%[5,10,11]$. Cessation of food intake, intravenous fluid replacement, measures taken against thromboemboli, antibiotherapy, and achievement of sufficient cardiac output in Grade III IC are curative in most of the cases. Patients are closely followed up for severe IC development. It is also suggested that the gangrenous segment is resected as soon as possible by laparotomy in severe IC cases $[1,5,11]$.

Treatment options for emergency and elective AAA have been frequently utilized at our hospital. A significant portion of these has recently been EVAR. The aim of this study was to investigate the effect of a ruptured abdominal aortic aneurysm on IC development, morbidity, and mortality.

\section{MATERIALS AND METHODS}

\section{Patients}

Between January 2012 and December 2016, patients who underwent resection for IC at our clinic were retro- spectively reviewed. The study included patients with infrarenal AAA surgery, those who underwent a resection because of IC, and those whose data were obtained. IC cases following suprarenal and thoracic aortic aneurysm surgery were excluded from the study. Furthermore, IC patients who underwent resections because of mesenteric ischemia, cardiac surgery, inflammatory bowel disease, abdominal surgery, volvulus and adhesions were excluded from the study. The consent of the Board of Ethics at Kartal Kosuyolu Higher Specialty Training and Research Hospital was also obtained.

\section{Data collection}

Data on the patients were collected through the investigation of the hospital's electronic archive system and patients' files. Basic data such as patients' age, sex, and body mass index (BMI) were recorded in addition to their comorbid conditions like hypertension, DM, smoking, CAD, peripheral vascular disease (PVD), COPD, and ASA (American Society of Anesthesiologists) scores. Data on the ruptured condition of an aneurysm, emergency or elective form of aneurysm surgery, and treatment method for an aneurysm (EVAR-open) were obtained from the surgical and epicrisis reports of the cardiovascular surgery (CVS) clinic. Data like inotropic support, amount of blood loss, and duration of surgery ( $\mathrm{min})$ during the surgical procedure for the treatment of aneurysm were obtained through the investigation of surgical notes and anesthesia follow-up forms. After aneurysm treatment, the first $24-\mathrm{h}$ unfractionated heparin infusion was provided to patients without active bleeding. Aspirin and low-molecular-weight heparin were then administered during hospitalization and discharged with aspirin. Thromboembolism prophylaxis was performed similarly for IC. Laboratory values before and $24 \mathrm{~h}$ after aneurysm surgery were recorded. Complications other than IC and related to AAA surgery [renal failure, hemorrhage, superior mesenteric artery occlusion, sepsis, lower extremity vascular obstruction, adult respiratory distress syndrome (ARDS), multiorgan failure syndrome (MOFS), pneumonia, wound site infection, spinal cord ischemia, cerebrovascular event] were recorded as well. The number of full blood and erythrocyte suspension administered to the patients during hospitalization was established through the comparison of data from the blood bank and the blood product confirmation form for the patient. Symptoms were seen prior to the gastrointestinal system (GIS) surgery, duration of 
the surgical procedures performed because of IC, and the aneurysm surgery were recorded (in days). The duration of hospitalization was set as the time from AAA surgery to discharge while mortality was set as mortality during hospitalization. The patients were compared and divided into 2 groups: those with a ruptured aneurysm and those without the aneurysm.

\section{Statistical analyses}

The Statistical Package for the Social Sciences (Chicago, IL, USA) software was utilized for biostatistical analyses. The data of the patients covered by the study were given in minimum and maximum values as well as in percentages, where necessary. Categorical groups were compared by the chi-squared test. Binary group comparisons of numeric data were performed by the Mann-Whitney U-test. Statistical significance was set at the $\mathrm{p}<0.05$ level.

\section{RESULTS}

A total of 275 infrarenal AAA cases were treated by the cardiovascular surgery clinic between January 2012 and December 2016. Fifty-seven (20.7\%) of these patients were treated by open surgery, while 218 (79.2\%) were treated by the EVAR method. Fourteen patients (5\%) developed IC requiring resection. Four (1.8\%) patients with EVAR and 10 (17.5\%) patients with open surgery were operated because of IC. The median age of the patients was 62.5 (40-85) years, and all were males. The most frequent comorbid conditions included hypertension (12/14), CAD (10/14), DM (5/14), and PVD (4/14). The ASA score of the patients was mostly III and IV. The results of the intergroup comparison demonstrated that all the patients with PVD were in the group with no ruptures $(p=0.04)$. There was no statistically significant difference between the groups with regards to age, other comorbid conditions, smoking, and ASA scores (Table 1).

Due to the ruptured aneurysm, $6(42.86 \%)$ patients were all treated under emergency conditions and 2 were treated by EVAR and 4 by an open surgical procedure. All 8 patients $(57.14 \%)$ without a ruptured aneurysm were scheduled operated. While the aneurysms of 2 of these patients were repaired by EVAR, 6 were repaired by open surgery. No statistically significant difference was found between the ruptured AAA group and the nonrupture group with regards to intraoperative blood loss, duration of operation, intraoperative inotropic support,

\begin{tabular}{|c|c|c|c|}
\hline Variable & $\begin{array}{l}\text { Without rupture } \\
(n=8,100 \%)\end{array}$ & $\begin{array}{l}\text { With rupture } \\
(n=6,100 \%)\end{array}$ & $\mathrm{p}$ \\
\hline $\begin{array}{l}\text { Median age, } \\
\text { years (min-max) }\end{array}$ & $60(48-85)$ & $65(40-82)$ & 0.998 \\
\hline \multicolumn{4}{|l|}{ Sex } \\
\hline M & $8(\%)$ & $6(\%)$ & - \\
\hline $\mathrm{F}$ & $0(\%)$ & $0(\%)$ & \\
\hline \multicolumn{4}{|l|}{ Comorbidities } \\
\hline HTN & $6(75 \%)$ & $6(100 \%)$ & 0.186 \\
\hline CAD & $6(75 \%)$ & $4(66.7 \%)$ & 0.733 \\
\hline DM & $3(37.5 \%)$ & $2(33.3 \%)$ & 0.872 \\
\hline $\mathrm{CHF}$ & $1(12.5 \%)$ & $2(33.3 \%)$ & 0.347 \\
\hline PVD & $4(50 \%)$ & 0 & $0.04^{*}$ \\
\hline $\mathrm{AF}$ & $1(12.5 \%)$ & 0 & 0.369 \\
\hline COPD & $1(12.5 \%)$ & $1(16.7 \%)$ & 0.825 \\
\hline Cigarette smoking & $4(50 \%)$ & $2(33.2 \%)$ & 0.533 \\
\hline BMI $\left(\mathrm{m}^{2} / \mathrm{kg}\right)$ & $23.8(18.5-30.4)$ & $27.2(22.4-30.8)$ & 0.194 \\
\hline \multicolumn{4}{|l|}{ ASA score } \\
\hline 1 & 0 & 0 & 0.211 \\
\hline 2 & $2(25 \%)$ & 0 & \\
\hline 3 & $4(50 \%)$ & $2(33.3 \%)$ & \\
\hline 4 & $2(25 \%)$ & $4(66.7 \%)$ & \\
\hline
\end{tabular}

AF, atrial fibrillation; ASA, American Society of Anesthesiologists; BMI, body massindex $\left(\mathrm{m}^{2} / \mathrm{kg}\right) ; C A D$, coronary artery disease; $\mathrm{CHF}$, congestive heart failure; COPD, chronic obstructive pulmonary disease; DM, diabetes mellitus; $F$, female; HTN, hypertension; M, male; PVD, peripheral vasculer disease; ${ }^{*}, \mathrm{p}<0.05$.

and the number of blood transfusions. The ruptured cases, however, were all taken into emergency surgery (Table 2). Table 3 presents the comparison of laboratory parameters of both groups before the aneurysm surgery and $24 \mathrm{~h}$ after surgery. The preoperative WBC value was $8.3 \times 10^{9} / \mathrm{L}(6.2-10.8)$ in the non-rupture group, while it was $11.4 \times 10^{9} / \mathrm{L}(8.4-15.9)$ in the rupture group and the difference between the 2 groups was statistically significant $(\mathrm{p}=0.01)$. The measured lactate value was 2.6 $\mathrm{mmol} / \mathrm{L}(1.1-10.7)$ in the ruptured AAA group, while it was $1.1 \mathrm{mmol} / \mathrm{L}(0.8-5.4)$ in the non-rupture group and the difference between the 2 was statistically significant as well $(\mathrm{p}=0.038)$ (Table 3$)$.

Among the symptoms seen prior to GIS surgery, the most common ones were abdominal pain and distension. The median value of the time between aneurysm surgery and GIS surgery was 5 (1-150) days in the rupture group, while it was 6 (3-90) days in the non-rupture group and the results were similar in both groups. One patient from both groups was operated on late due to 
stenosis. Five $(62.5 \%)$ patients in the non-rupture group received the Hartmann procedure, 2 (25\%) patients underwent right colectomy with partial small bowel resection, and 1 patient underwent total colectomy. Five $(83.3 \%)$ patients in the rupture group received the Hart-

TABLE2. Data related to aneurysm surgery

\begin{tabular}{lccc} 
Variable & $\begin{array}{c}\text { Without Rupture } \\
(\mathrm{n}=8,100 \%)\end{array}$ & $\begin{array}{c}\text { With Rupture } \\
(\mathrm{n}=6,100 \%)\end{array}$ & $\mathrm{p}$ \\
\hline EVAR** & $2(25 \%)$ & $2(33.3 \%)$ & 0.733 \\
Open surgery & $6(75 \%)$ & $4(66.7 \%)$ & 0.733 \\
Emergency & 0 & $6(100 \%)$ & $0.001^{*}$ \\
Elective & $8(100 \%)$ & 0 & $0.001^{*}$ \\
Intraoperative & $1050(340-2500)$ & $1250(350-3200)$ & 0.897 \\
blood loss (ml) & & $2(33.3 \%)$ & 0.347 \\
Inotrop support & $1(12.5 \%)$ & $270(140-600)$ & 0.438 \\
Surgery time & $340(120-560)$ & & \\
(minute) & & $12(6-32)$ & 0.196 \\
$\begin{array}{l}\text { Transfusion } \\
\text { (unit) }\end{array}$ & $3(0-61)$ & & \\
\hline
\end{tabular}

**, EVAR, endo vasculer aneurysm repair; *, $\mathrm{p}<0.05$.

TABLE 3. Laboratory data before and 24 hours after aneurysm surgery in groups

\begin{tabular}{lccc} 
Variable & $\begin{array}{c}\text { Without Rupture } \\
(\mathrm{n}=8)\end{array}$ & $\begin{array}{c}\text { With Rupture } \\
(\mathrm{n}=6)\end{array}$ & $\mathrm{p}$ \\
& & & \\
\hline Preoperative & & & \\
WBC $\left(\times 10^{9} / \mathrm{L}\right)$ & $8.3(6.2-10.8)$ & $11.4(8.4-15.9)$ & $0.01^{*}$ \\
Htc $(\%)$ & $38(26-45)$ & $41(26-48)$ & 0.651 \\
Platalet $\left(\times 10^{9} / \mathrm{L}\right)$ & $229(21-354)$ & $220(139-233)$ & 0.606 \\
Lactate $(\mathrm{mmol} / \mathrm{L})$ & $1.1(0.8-5.4)$ & $2.6(1.1-10.7)$ & 0.038 \\
Urea $(\mathrm{mg} / \mathrm{dL})$ & $42(22-55)$ & $54(25-67)$ & 0.053 \\
Creatinine $(\mathrm{mg} / \mathrm{dL})$ & $1.1(0.6-1.4)$ & $1.4(0.9-1.8)$ & 0.169 \\
CRP $(\mathrm{mg} / \mathrm{dl})$ & $2(0,2-19)$ & $1(0.3-5)$ & 0.699 \\
Postoperative & & & \\
After $24 \mathrm{hours})$ & & & \\
WBC $\left(\times 10^{9} / \mathrm{L}\right)$ & $14.8(11.2-17.7)$ & $12.6(5.2-20.1)$ & 0.560 \\
Htc $(\%)$ & $31(24-36)$ & $31(18-42)$ & 0.99 \\
Platalete $\left(\times 10^{9} / \mathrm{L}\right)$ & $118(70-138)$ & $140(76-251)$ & 0.064 \\
Lactate $(\mathrm{mmol} / \mathrm{L})$ & $2.8(1.2-7.9)$ & $2.9(1.8-24)$ & 0.841 \\
Urea $(\mathrm{mg} / \mathrm{dL})$ & $52(35-88)$ & $177(41-145)$ & 0.358 \\
Creatinine $(\mathrm{mg} / \mathrm{dL})$ & $1.5(1-2.3)$ & $1.6(1.1-3.4)$ & 0.998 \\
CRP $(\mathrm{mg} / \mathrm{dL})$ & $14(4-26)$ & $10(1-24)$ & 0.467
\end{tabular}

CRP: C-reactive protein (normal range: $0-0.34 \mathrm{mg} / \mathrm{dL}$ ). Htc: Hematocrite (normal range: 33-54\%), WBC: Peripheral white blood cell count: *, $p<0.05$. mann procedure, while one patient had right colectomy alongside with segmental small bowel resection. Two patients had segmental small bowel resection by relaparatomy. The intergroup comparison did not reveal any statistically significant difference among GIS symptoms, the time period until surgery, the involved colon segment, and the surgical procedures performed (Table 4).

All the patients contracted complications, except IC, following aneurysm surgery. Renal failure was seen in 10 patients, while sepsis in 7, MOFS in 4, bleeding in the early postoperative period in 3 , wound site infection and evisceration in 3, pneumonia in 3, spinal cord ischemia in 2 , and SVO in 2 patients was observed. Table 5 summarizes the data on all complications. Both groups had similar durations of intensive care and hospitalization. Five patients in each group had mortality. The mortality rate in ruptured AAA group was $83.3 \%$, while it was $62.5 \%$ in the non-ruptured AAA group. In spite of the fact that the mortality rate was high in the ruptured group, it was not statistically significant $(p=0.393)$.

TABLE 4. Symptoms, surgical procedures and results of ischemic colitis

\begin{tabular}{lccc} 
Variable & $\begin{array}{c}\text { Without rupture } \\
(\mathrm{n}=8,100 \%)\end{array}$ & $\begin{array}{c}\text { With rupture } \\
(\mathrm{n}=6,100 \%)\end{array}$ & $\mathrm{p}$ \\
\hline Abdominal pain & $6(75 \%)$ & $2(33.3 \%)$ & 0.119 \\
Distension & $4(50 \%)$ & $4(66.7 \%)$ & 0.533 \\
Rectal bleeding & $1(12.5 \%)$ & 0 & 0.369 \\
$\begin{array}{l}\text { Intestinal contents } \\
\text { coming from }\end{array}$ & $1(12.5 \%)$ & $1(16.7 \%)$ & 0.825 \\
the incision & & & \\
Time between & $6(3-90)$ & $5(1-150)$ & 0.399 \\
aneurysm surgery & & & \\
and gastrointestinal & & & \\
surgery (day) & & & \\
Surgical procedure & & & \\
$\quad$ Hartman procedure & $5(62.5 \%)$ & $5(83.3 \%)$ & 0.393 \\
$\quad$ Right colectomy+ & $2(25 \%)$ & $1(16.7 \%)$ & 0.707 \\
$\quad$ small bowel resection & & & \\
$\quad$ Total colectomy & $1(12.5 \%)$ & 0 & 0.369 \\
$\quad$ Stoma & $7(87.5 \%)$ & $6(100 \%)$ & 0.369 \\
$\begin{array}{l}\text { Days in ICU (day) } \\
\text { Length of stay in }\end{array}$ & $13(1-37)$ & $16(2-39)$ & 0.605 \\
hospital (day) & $15(5-49)$ & $17(2-39)$ & 0.983 \\
Mortalite & $5(62.5 \%)$ & $5(83.3 \%)$ & 0.393 \\
\hline
\end{tabular}

ICU, Intensive care unit. 


\section{DISCUSSION}

The full-thickness colon necrosis with AAA perforation, which has high rates of morbidity and mortality, still proves to be a significant complication. Ruptured AAA and emergency surgical procedures increase the risk of IC $[6,12]$. IC still continues to be an important cause of deaths in aortic aneurysm surgery based on its low incidence rate, challenging diagnosis, and destructive results. It has to be identified early giving way to the resection of the gangrenous segment with maximal borders before MOFS develops $[1,13]$. The incidence of IC has decreased considerably as the utilization of EVAR as a treatment modality has increased. IC is seen between $0.5 \%$ and $4 \%$ after EVAR $[11,14]$. In our study, 14 patients $(5 \%)$ developed IC requiring resection. Four (1.8\%) patients with EVAR and $10(17.5 \%)$ patients with open surgery were operated because of IC. Open surgery is frequently performed on patients with ruptured AAA who are generally hemodynamically unstable under emergency conditions, which in turn increases the incidence of IC. In a study by Champagne et al [10], the authors reported that $14 \%$ of 88 patients, who had an emergency open surgery because of ruptured AAA, had Grade III IC. Becquemin et al. [2] also stated that 12.5\% of the patients in their ruptured AAA group had IC, while $2 \%$ of the patients in the non-rupture group had IC.

The formation of colonic ischemia has been explained by many factors. The closure of the IMA, microembolization, embolization of the hypogastric artery, placement of cross-clamp into the aorta, intraoperative traumatization of the colon, compressive effect because of retroperitoneal hematoma, prolonged hypotension, and ischemia-reperfusion damage are listed among its causes $[1,2,8,11,13$, 15]. Many risk factors in the formation of IC have also been reported in various studies. In their study with a large population, Moghadamyeghaneh et al. [3] ascertained that preoperative rupture of an aneurysm, the need for blood transfusion, aneurysm's going above the renal level, renal failure, diabetes, and female sex were determinant in IC formation. In a current meta-analysis by Lee et al. [6], the authors stated that emergency presentation and open surgery proved to be 2 significant risk factors in IC formation. The same meta-analysis also referred to old age, female sex, hypotension, and the need for massive blood transfusion as risk-increasing factors. Our study was not appropriate to determine risk factors as no comparisons were made with patients who did not undergo surgery because of IC. Ten (71.4\%) patients with IC, however, had aneurysm repair by open surgery. Ruptured aneurysm was not ascertained to be a risk factor for IC in this study. Some studies have reported that lactate levels $>2.5 \mathrm{mmol} / \mathrm{L}$ in IC cases were related to mortality $[9,16]$. It was seen in our study that lactate levels and WBC counts measured before aneurysm surgery in the rupture group were significantly higher than those of the non-rupture group ( $\mathrm{P}$ value $=0.038$ and 0.01 respectively). This difference, however, was observed on the first postoperative day, and it was seen that it had no effect on the results.

A total of 46 complications occurred in 14 patients who underwent surgery for IC. (Table 5). Among the complications observed and proved to be significant included renal failure in 10 patients, sepsis in 7, MOFS in 4 , bleeding in the early postoperative period in 3 , wound site infection and evisceration in 3, pneumonia in 3 , spinal cord ischemia in 2, SVO in 2, and ARDS in 2. Alongside with the fact that IC on its own is an important cause of mortality, these complications are also serious problems contributing to the increase in mortality. It was seen that mortality was higher ( $83.3 \%$ vs. $62.5 \%)$ in the ruptured aneurysm group but this difference was not statistically significant $(\mathrm{p}=0.393)$. Our study has serious limitations among which it being retrospective, limited

TABLE 5. Postoperative complications

Complications

n

Acut renal failure

10

Sepsis

MOFS

Hemorrhage

Pneumonia

Evisceration

Wound infection

ARDS

SVE

Spinal cord ischemia

Myocardial infarction

SMA occlusion

Lower Extremity arterial thrombosis

Thoracotomy (hemorrhge)

DIC

Ventricular fibrillation

Decubitus ulcers

7

4

3

3

3

3

2

2

ARDS, Adult respiratuar distress syndrome; DIC, disseminated intravascular coagulation; MOFS, Multiorgan failure syndrome; SMA, Superior mesenteric artery; SVE, Cerebrovascular event. 
number of cases, absence of data on IC patients not necessitating resection, inability to compare data with the non-IC group, and the absence of long-term follow-up results can be listed.

\section{CONCLUSION}

IC is a complication of AAA surgery with a high mortality rate. Mortality is increased in patients who develop IC in a ruptured abdominal aortic aneurysm. Its incidence with EVAR is quite rare and it still is a frequent problem in open aneurysm surgery. This complication with a high mortality rate following open AAA surgery should be noted by surgeons and we believe that the liberal utilization of laparotomy and early intervention in suspected cases will decrease mortality rates.

Conflict of Interest: The authors declare no conflict of interest.

Financial Disclosure: The authors declared that this study has received no financial support.

Authorship Contributions: Concept - U.A., E.B., E.P.; Design U.A., D.A.C., H.C., A.S.S., S.G.; Supervision - E.P., M.A., E.G., A.S.S.; Materials - U.A., M.A., S.G., D.A.C.; Data collection \&/or processing - U.A., E.P., M.A., S.G., H.C., D.A.C.; Analysis and/or interpretation - U.A., E.G.,H.C.; Writing - U.A., E.G., D.A.C.; Critical review - E.P., A.S.S., S.G.

\section{REFERENCES}

1. Steele SR. Ischemic colitis complicating major vascular surgery. Surg Clin Am 2007;87:1099-114. [CrossRef]

2. Becquemin JP, Majewski M, Fermani N, Marzelle J, Desgrandes P, Allaire E, et al. Colon ischemia following abdominal aortic aneurysm repair in the era of endovascular abdominal aortic repair. J Vasc Surg 2008;47:258-63. [CrossRef]

3. Moghadamyeghaneh Z, Sgroi MD, Chen SL, Kabutey NK, Stamos MJ, Fujitani RM. Risk factors and outcomes of postoperative ischemic colitis in contemporary open and endovascular abdominal aortic aneurysm repair. J Vasc Surg 2016;63:866-72. [CrossRef]

4. Davidovic LB, Maksic M, Koncar I, Ilic N, Dragas M, Fatic N, et al. Open repair of AAA in a high volume center. World J Surg 2017;41:884-91.

5. Moszkowicz D, Mariani A, Trésallet C, Menegaux F. Ischemic colitis: the ABCs of diagnosis and surgical management. J Visc Surg 2013;150:19-28, [CrossRef]

6. Lee MJ, Daniels SL, Drake TM, Adam IJ. Risk factors for ischaemic colitis after surgery for abdominal aortic aneurysm: a systematic review and observational meta-analysis. Int J Colorectal Dis 2016;31:127381. [CrossRef]

7. Neary P, Hurson C, Briain DO, Brabazon A, Mehigan D, Keaveny TV, et al. Abdominal aortic aneurysm repair and colonic infarction: a risk factor appraisal. Colorectal Dis 2007;9:166-72. [CrossRef]

8. Toya N, Baba T, Kanaoka Y, Ohki T. Embolic complications after endovascular repair of abdominal aortic aneurysms. Surg Today 2014;44:1893-9. [CrossRef]

9. Genstorfer J, Schafer J, Kettelhack C, Oertli D, Rosenthal R. Surgery for ischemic colitis: outcome and risk factors for in-hospital mortality. Int J Colorectal Dis 2014;29:493-503. [CrossRef]

10. Champagne BJ, Darling RC, Daneshmand M, Kreienberg PB, Lee EC, Mehta $\mathrm{M}$, et al. Outcome of aggressive surveillance colonoscopy in ruptured abdominal aortic aneurysm. J Vasc Surg 2004;39:792-6. [CrossRef]

11. Brandt LJ, Feuerstadt P, Longstreth GF, Boley SJ; American College of Gastroenterology. ACG clinical guideline: epidemiology, risk factors, patterns of presentation, diagnosis, and management of colon ischemia (CI). Am J Gastroenterol 2015;110:18-44. [CrossRef]

12. Perry RJ, Martin MJ, Sohn VY, Steele SR. Colonic ischemia complicating open vs endovascular abdominal aortic aneurysm repair. J Vasc Surg 2008;48:272-7. [CrossRef]

13. Darras S, Paineau J, Patra P, Goueffic Y. Prognostic factors of ischemic colitis after infrarenal aortic surgery. Ann Vasc Surg 2011;25:612-9.

14. Reimerink JJ, Hoornweg LL, Vahl AC, Wisselink W, van den Broek TA, Legemate DA, et al; Amsterdam Acute Aneurysm Trial Collaborators. Endovascular repair versus open repair of ruptured abdominal aortic aneurysms: a multicenter randomized controlled trial. Ann Surg 2013;258:248-56. [CrossRef]

15. Miller A, Marotta M, Scordi-Bello I, Tammaro Y, Marin M, Divinp C. Ischemic colitis after endovascular aortoiliac aneurysm repair: a 10-year retrospective study. Arch Surg 2009;144:900-3. [CrossRef]

16. Reissfelder C, Sweiti H, Antolovic D, Rahbari NN, Hofer S, Büchler MW, et al. Ischemic colitis: Who will survive? Surgery 2011;149:58591. [CrossRef] 